\title{
An Analytical Study on Management of Eco-Friendly Practices of Vegetable Crops among the Tribal farmers of Madhya Pradesh, India
}

\author{
Jagdish Morya ${ }^{1}$, D. P. Rai ${ }^{1}$ and S. K. Badodiya ${ }^{2 *}$ \\ ${ }^{1} M G C G V V$ Chitrakoot, India \\ ${ }^{2}$ RVSKVV KVK Barwani MP, India \\ *Corresponding author
}

\begin{abstract}
A B S T R A C T
The vegetables now become a crucial requisite of the daily human diet, because of its nutritional value. The present investigation was conducted in four tribal district of Madhya Pradesh. Total sixteen villages were selected for the study. There was proportional to total size of the respondents in selected villages fell under each of the four blocks. In all, 240 tribal farmers were selected to serve as the respondents for the study. Higher percentage (49.17) of the respondents had medium adoption about eco friendly practices. A preponderance of the farmers 70.84 percent had partially adopted farm yard manure application. Most of the respondents 52.50 and 36.67 percent of the respondents had adopted crop rotation and inter cropping practices in vegetable. Majority of the farmers (75.83\%) had not applied any biofertilizer for growing vegetables. higher proportion of the respondents partially adopted the practices like splitting dose of application (60.83\%). Massive majority 97.92 percent farmers were found in non-adoption category regarding use of pheromone traps and use of light traps. Hundred percent of the farmers were found in non adoption category regarding practices such as conservation parasitic wasps. Majority 92.50 percent of the farmers had fully adopted the practices like use of hand weeding in standing crop closely. Majority 85.41 percent of the respondents suggested to ensure timely availability of pest resistant improved varieties, followed by three-fourth of respondents said organizing awareness campaign on eco-friendly practices $(75.83 \%)$.
\end{abstract}

\section{Keywords}

Management, Ecofriendly practices, Tribal farmers, INM, IPM parasitic wasps and biocontrol agents

Article Info

Accepted:

26 March 2020 Available Online: 10 April 2020

\section{Introduction}

Tribal main source of livelihood was agriculture. However, hunter-gatherers or herders were also there. Some tribes were traveling and kept on moving from one place to another. Many large tribes lived in forest, hills, deserts, and places difficult to reach. Madhya Pradesh has a total population of 7.25 crore which constitutes about 6 per cent of total population of India, according to the latest 2011 census. Tribes constitute about 20 
per cent of the total population of MP. The key eco-friendly expertise's merit mentioning are organic farming, traditional farming, natural farming, sustainable farming, biodynamic and pharma culture, which can be all collectively considered as eco-friendly farming. Disorganized use of high analysis fertilizers has caused several problems on farm as well as outside farm. Plants become more susceptible to pests and diseases and their control could be effectively done by using high potency poisonous chemicals. As a result, their residue on plants and in the soil had led to health hazards. Similarly, excess nitrogen as nitrate and phosphate leached through the soil and entered natural sources of drinking water also responsible for health hazards.

The chemical detrimental effects of fertilizers in plants are reduction in germination, retardation in seedling growth, scorching and increased susceptibility to diseases. Study within the field of agriculture has recognized variety of environmental friendly technologies like eco-farming, eco-friendly nutrient management. The eco-farming consumes most efficiently the normal practices of crop rotations with legumes, tillage practices to recover soil texture, application of ample organic matter to sustain, maintain and discharge soil moisture, nutrient to match crop requirements and correlation features of soil unhealthiness. There have been hardly any research studies, which have attempted to explore the knowledge of tribal farmers about the environmental hazards and eco-friendly management practices and the status of eco-friendly practices followed by farmers with the following objectives-1. To study the extent of adoption of vegetable growing tribal farmers about eco-friendly management practices. 2. To explore the association between personal and socioeconomic traits of vegetable growing tribal farmers with their adoption of eco-friendly management practices. 3 . To seek suggestive measure to minimize the ill effect of agrochemicals as perceived by vegetable growing tribal farmers.

\section{Materials and Methods}

The present study was conducted in four selected blocks of four district i.e. Jhabua from Jhabua district, Manawar from Dhar district, Jobat from Alirajpur districts and Rajpur from Badwani districts respectively and in this consequences four villages from each of the selected blocks were selected randomly. Thus, in total sixteen villages were selected for the study. A proportionate random sampling process was adopted for the selection of tribal farmers for cultivating vegetable crops. A list of tribal farmers, those who had cultivated vegetable crops for three or more than three years successively, was prepared. A special interview schedule was designed for collecting the data through interview schedule.

The entire schedule was pre-tested in the field with 20 non-sampled respondents were classified to remove irrelevant items which were included in the interview schedule. Based on responses received and experience gained, the necessary modifications were incorporated in the final draft. The data were composed by personal interview technique from randomly selected tribal farmers of the selected districts. The respondents were contacted at their home, community places or their farms.

\section{Results and Discussion}

A general and concise sketch of respondents on the root of their level of knowledge about eco-friendly management practices. It refers to information about eco friendly practices known to respondents. The farmers were categorized on the root of their obtained score 
of adoption about management of ecofriendly practices.

Adoption of eco-friendly management practices by the respondents

It refers to information about eco friendly practices known to respondents. The respondents were categorised on the root of their obtained score of knowledge.

The data in Table 1 and Figure 1 showed that out of the total 240 respondents, the higher percentage 49.17 percent respondents were in the medium category of adoption about eco friendly practices followed by 31.67 percent were in the low and only 19.16 percent were in high adoption about eco friendly practices. The sample mean of adoption about ecofriendly management practices of the respondents was found 1.31. Standard deviation 0.81 was calculated of the quantity of disproportion or distribution of a set of ethics of vegetable growing tribal farmers. Thus, it can be accomplished that higher percentage of the respondents had medium adoption about eco friendly practices.

This result revels in the line of work done by Badodiya et al., (2010); Gour et al., (2014); and Maratha and Badodiya (2018).

Table.1 Frequency distribution of farmers according to the adoption eco-friendly management practices

\begin{tabular}{|c|c|c|c|}
\hline S. No. & Categories & \multicolumn{2}{|c|}{ Respondents $(\mathbf{n = 2 4 0})$} \\
\hline 1. & Low & 76 & Prequency \\
\hline 2. & Medium & 118 & 31.67 \\
\hline 3. & High & 46 & 49.17 \\
\hline & Total & $\mathbf{2 4 0}$ & 19.16 \\
\hline & Mean & & $\mathbf{1 0 0 . 0 0}$ \\
\hline & SD & $\mathbf{1 . 3 0}$ & \\
\hline
\end{tabular}

Fig.1 Frequency distribution of respondents according to their adoption EFPs management practices

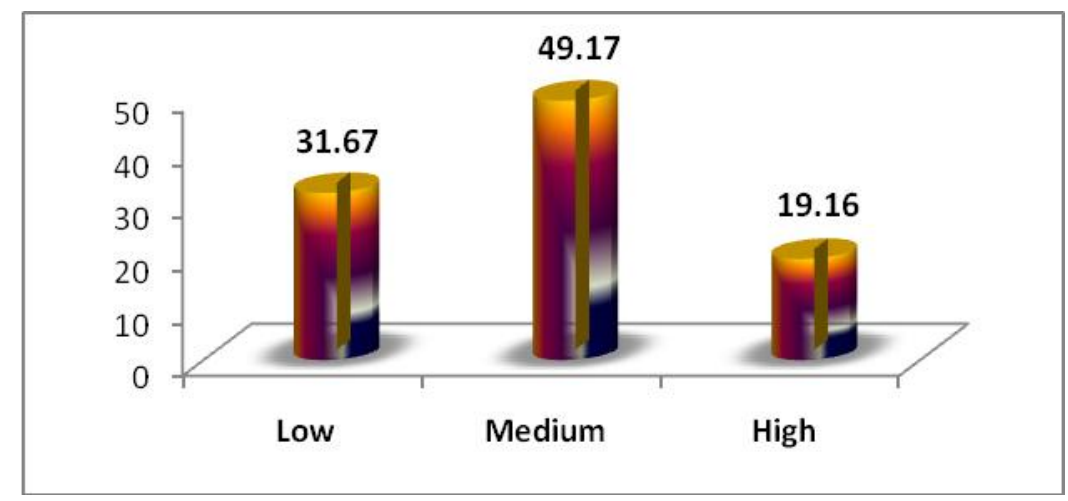


Extent of adoption of integrated nutrient management (INM) practices by vegetable growing tribal farmers

The statistics depicted in Table 2 that the adoption of different mechanism of integrated nutrient management practices by the vegetable growing tribal farmers.

\section{Utilization of organic manure}

A preponderance of the farmers 70.84 percent had partially adopted farm yard manure application. None of them applied poultry manure and compost, while 75.00, 85.00 and 88.33 percent of them never applied green manure, vermicompost and seeds cake and press mud cake in vegetable crops.

No knowledge about potentiality of green leaf manure, poultry manure, compost, vermicompost, also their non-availability and high cost were the main motives for majority of the respondents not adopting the above practices. Hence, extension workers require educating the vegetable growing respondents about the beneficial effects of the green leaf manure, poultry manure, compost and vermicompost by conducting results demonstration on farmer's field.

Management in selection of crops and cropping pattern

The data shows that 52.50 and 36.67 percent of the respondents had adopted crop rotation and inter cropping practices in vegetable. None of the respondents had adopted mixed cropping systems in vegetable. Further, about 65.00 percent of respondents did not practice intercropping. The possible reason might be that vegetables are short duration crops and difficult to undertake intercultural practices. Hence, majority of the vegetable growing respondents had not practiced intercropping with other crops in vegetables.

\section{Management of intercultural practices}

The examination of information offered in Table 2 points out that $95.00,78.33$ and 54.16 percent of the respondents never adopted the intercultural practices like maintaining of optimal soil moisture to keep away from the leaching and mobility of nutrients, incorporation of crop dregs and timely weeding, respectively.

The non-adoption of intercultural practice like incorporation of crop remains might be due to lack of awareness and knowledge about the benefits of incorporation of crop dregs. The respondents had perceive that burning crop residues compose the field free from pests and diseases and also they perceive that burning crop residues facilitates easy land preparation and inter-cultivation practices for succeeding crop.

\section{Utilization of natural resources}

In case of utilization of natural resources, only 15.00 percent of the farmers had fully adopted the practice of using tank silt/ forest litter (leaves) to their land, while, 79.17 percent of them did not apply. In addition to this, cent percent and 92.50 percent of them did not use rock phosphate and gypsum at all. The probable reason might be the nonavailability of tank silt and forest litter as the main reason for non-application. Whereas, regarding gypsum it is costly and used only for problematic soils.

\section{Management in application of bio-fertilizer}

Majority of the farmers $(75.83 \%)$ had not applied any bio-fertilizer for growing vegetables (Table 2). The possible reason might be lack of knowledge, high cost and their neglect use of bio-fertilizers by the farmers. 


\section{Utilization of inorganic manures}

In case of utilization of inorganic manures, higher proportion of the respondents partially adopted the practices like splitting dose of application $(60.83 \%)$ and use of recommended dose of fertilizer $(41.67 \%)$. While, 90.00 percent of vegetable growing respondents followed for applying right method. About 44.17 percent of vegetable growing respondents did not timely apply inorganic fertilizers. Thus, it is concluded on the basis of above results that mainstream of the respondents not applied recommended dose of fertilizers and timely application whereas, half of the respondents fully adopted of split application of fertilizers on the vegetable crops. Lack of knowledge, high cost of fertilizers might have resulted in such a situation. It is therefore, very necessary for using balance as well as recommended dose of fertilizers and these might be promoted through discussion, training and demonstration, meeting etc. The department of horticulture had to play key role in this regard.

Adoption of integrated management practices (IPM) by vegetable growing tribal farmers

The data portrayed in Table-3 reveals the adoption of eco-friendly management practices by vegetable growing respondents with respect to IPM.

\section{Management of cultural practices}

In case of management of cultural practices, a huge majority 95.83 percent of the vegetable growing respondents adopted deep ploughing in summer which is a significant method of revealing the early stages of insect and pest to sun for natural annihilation and making the soil to a fine tilth for escalating the soil fertility and for superior germination of seeds.
Crop rotation in vegetable was also followed by 95.83 percent of the farmers.

In assumption of practices such as, use of pest and anti disease varieties, seed treatment with bio-fertilizers, trap cropping, use of intercropping and installation of bird perches for predatory birds, $60.00,83.33,79.16,85.83$ and 100.00 percent of the respondents, respectively were found in non adoption category. Effortless availability of urea and other nitrogenous fertilizers performed as obstruction switching over to the use of biofertilizers.

\section{Management of mechanical practices}

Regarding management of mechanical practices; about 44.17 percent of respondents fully adopted the practices like uprooting, alternate host plants, while, 41.67 and 40.00 percent of them were found in partially adoption category in case of monitoring of pests and collection and destruction of affected plant parts and shoots, respectively.

Massive majority 97.92 percent farmers were found in non-adoption category regarding use of pheromone traps and use of light traps whereas, 91.67 percent of the farmers never used the yellow sticky traps in their fields. This might be because, the use and maintenance of pheromone and light traps required good care on the part of the farmers, required periodical replacement of the lure and their non availability. Furthermore, 58.33 and 55.83 percent of respondents were also found to be in non-adoption category regarding monitoring of pests and uprooting alternate host plants, respectively.

\section{Management of biological control}

Regarding management of biological control; hundred percent of the farmers were found in non adoption category regarding practices 
such as conservation parasitic wasps followed by 97.92 percent of the respondents had conserved and encouraging predators, whereas, only 01.67 percent respondents had introduced of bio-control agents. This might be due to farmers' resorted to indiscriminate use of insecticides for immediate and effective control. The farmers had lack of technological skill in managing and using them in preservation of natural rivals. Moreover, the farmers might not have influenced about this practice due to unhurried impact on control of pests and intangible nature.

\section{Management in use of bio-pesticides}

On the assumption of management of biopesticides, mainstream of the farmers were found in non adoption category regarding use of neem seed kernel extract for worms and white flies (58.33\%), use of neem cake/bar to control nematodes/ root diseases $(79.16 \%)$, use of cow dung slurry $(65.83 \%)$ and application of ash (68.33\%). It is noticeable that the bio-control procedures are the pioneering practices and vegetable producing respondents might lack of the scientific awareness about their use. Additionally, nonavailability of bio-control agents might be the possible reason behind low acceptance of biopesticides.

The most probable reason for non-adoption of ash and cow dung could be emphasized to its non-technical and unscientific way of pest control, which lacked to evince interest in farmers.

\section{Management of weed practices}

It is pragmatic that vast majority 92.50 percent of the farmers had fully adopted the practices like use of hand weeding in standing crop closely followed by keeping bunds free from weeds $(91.66 \%)$.
Normally weeding procedure was assumed by the vegetable producing farmers for which hand hoes were used. These were miniature and uncomplicated to grip by the women labours. Further, 53.33 percent of farmers were found to have partial adoption of timely inter cultivation practices. Majority 93.33 percent of the respondents were not used the bio-herbicides for controlling the weeds.

The results support with the effort of Maratha et al., (2018) Maratha and Badodiya (2018) and Rajasree et al., (2019).

\section{Association between adoption about management of EFPs of tribal farmers with their profile}

The outcomes of our qualitative meta-analysis aiming at explaining the similar results in terms of geographical context and temporal trends are summarized in Table- 4 while the specific references to the reviewed literature are accounted.

Age and family size were found no significant association with adoption about eco friendly management practices. Education, social participation, size of land holding, annual income, economic motivation, irrigation availability, material possession, source of information, extension contact, innovativeness, cosmopoliteness, scientific orientation, market orientation and attitude towards vegetable cultivation were found significant association with adoption about eco friendly management practices.

The findings support with the work of Shashidhara and Manjunath (2008); Maratha et al., (2018); Gour et al., (2014); Maratha and Badodiya (2018) and Rajasree et al., (2019). 
Table.2 Extent of adoption of eco friendly practices (INM) by vegetable growers

\begin{tabular}{|c|c|c|c|c|c|c|c|}
\hline \multirow[t]{2}{*}{ S.N. } & \multirow[t]{2}{*}{ Integrated nutrient management practices } & \multicolumn{2}{|c|}{ Full adoption } & \multicolumn{2}{|c|}{ Partial adoption } & \multicolumn{2}{|c|}{ Non adoption } \\
\hline & & Frequency & Percent & Frequency & Percent & Frequency & Percent \\
\hline $\mathbf{I}$ & Utilization of organic manure & & & & & & \\
\hline i & Utilization of farmyard manure $(5 \mathrm{t} / \mathrm{ha})$ & 70 & 29.16 & 170 & 70.84 & - & - \\
\hline ii & Utilization of green manure $(2.5 \mathrm{t} / \mathrm{ha})$ & 20 & 8.33 & 40 & 16.67 & 180 & 75.00 \\
\hline iii & Utilization of poultry manure $(2 \mathrm{t} / \mathrm{ha})$ & - & - & - & - & 240 & 100 \\
\hline iv & Utilization of compost $(2.5 \mathrm{t} / \mathrm{ha})$ & - & - & - & - & 240 & 100 \\
\hline $\mathbf{v}$ & Utilization of vermicompost ( $2 \mathrm{t} / \mathrm{ha})$ & 24 & 10.00 & 12 & 5.00 & 204 & 85.00 \\
\hline vi & Utilization of seeds cake/ press mud & 12 & 5.00 & 16 & 6.67 & 212 & 88.33 \\
\hline II & Selection of crops and cropping pattern & & & & & & \\
\hline i & Crop rotation with legumes crops & 126 & 52.50 & - & - & 114 & 47.50 \\
\hline ii & Inter cropping & 84 & 35.00 & - & - & 156 & 65.00 \\
\hline iii & Mixed farming & - & - & - & - & 240 & 100 \\
\hline III & Intercultural practices & & & & & & \\
\hline $\mathbf{i}$ & Inclusion of crop residues & 40 & 16.67 & 12 & 5.00 & 188 & 78.33 \\
\hline ii & $\begin{array}{l}\text { Maintaining of optimum soil moisture to avoid } \\
\text { leaching and mobility of nutrients }\end{array}$ & 12 & 5.00 & - & - & 228 & 95.00 \\
\hline iii & Timely weeding & 90 & 37.50 & 20 & 8.34 & 130 & 54.16 \\
\hline IV & Utilization of natural resources & & & & & & \\
\hline $\mathbf{i}$ & Tank silt/ forest litter (leaves) & 36 & 15.00 & 14 & 5.83 & 190 & 79.17 \\
\hline ii & Utilization of rock phosphate & - & - & - & - & 240 & 100 \\
\hline iii & Utilization of gypsum & - & - & 18 & 7.50 & 222 & 92.50 \\
\hline $\mathbf{V}$ & Application of bio-fertilizers & 34 & 14.17 & 24 & 10.00 & 182 & 75.83 \\
\hline VI & Utilization of inorganic fertilizer & & & & & & \\
\hline $\mathbf{i}$ & $\begin{array}{l}\text { Application of } 50 \% \text { of recommended dose of } \\
\text { fertilizers with organic manures }\end{array}$ & 52 & 21.67 & 100 & 41.67 & 88 & 36.66 \\
\hline ii & Timely application & 60 & 25.00 & 74 & 30.83 & 106 & 44.17 \\
\hline iii & Right method of application & 216 & 90.00 & - & - & 24 & 10.00 \\
\hline iv & Split dose of application & 120 & 50.00 & 102 & 42.50 & 18 & 7.50 \\
\hline
\end{tabular}


Table.3 Extent of adoption of eco-friendly practices (IPM) by vegetable growers

\begin{tabular}{|c|c|c|c|c|c|c|c|}
\hline \multirow[t]{2}{*}{ S.N. } & \multirow[t]{2}{*}{ Integrated pest management practices } & \multicolumn{2}{|c|}{ Full adoption } & \multicolumn{2}{|c|}{ Partial adoption } & \multicolumn{2}{|c|}{ Non adoption } \\
\hline & & Frequency & Percent & Frequency & Percent & Frequency & Percent \\
\hline I & Management of cultural practices & & & & & & \\
\hline $\mathbf{i}$ & Deep ploughing in summer & 230 & 95.83 & 10 & 4.17 & - & - \\
\hline ii & Use of pest and disease resistant varieties & 96 & 40.00 & - & - & 144 & 60.00 \\
\hline iii & Seed treatment with bio-fertilizers & 40 & 16.67 & - & - & 200 & 83.33 \\
\hline iv & Crop rotation & 230 & 95.83 & - & - & 10 & 4.17 \\
\hline $\mathbf{v}$ & Trap cropping & 28 & 11.67 & 22 & 9.17 & 190 & 79.16 \\
\hline vi & Inter cropping & 34 & 14.17 & - & - & 206 & 85.83 \\
\hline vii & Installation of bird perches for predatory birds & - & - & - & - & 240 & 100 \\
\hline II & Management of mechanical practices & & & & & & \\
\hline $\mathbf{i}$ & Uprooting alternate host plant & 106 & 44.17 & - & - & 134 & 55.83 \\
\hline ii & Monitoring of pests & - & - & 100 & 41.67 & 140 & 58.33 \\
\hline iii & Collection and destruction of affected plant parts & 48 & 20.00 & 96 & 40.00 & 96 & 40.00 \\
\hline iv & Use of pheromone trap & 5 & 02.08 & - & - & 235 & 97.92 \\
\hline $\mathbf{V i}$ & Use of light traps to attract nocturnal insect and pests & 5 & 02.08 & - & - & 235 & 97.92 \\
\hline $\mathbf{V i}$ & Use of yellow sticky traps/cards & 15 & 06.25 & 5 & 02.08 & 220 & 91.67 \\
\hline III & Management of biological pest control & & & & & & \\
\hline $\mathbf{i}$ & Conservation and encouraging of predators in the field & 5 & 2.08 & - & - & 235 & 97.92 \\
\hline ii & Conservation of parasitic wasps & - & - & - & - & 240 & 100 \\
\hline iii & Introduction of bio-control agent & 4 & 01.67 & - & - & 236 & 98.33 \\
\hline IV & Management in use of bio-pesticides & & & & & & \\
\hline $\mathbf{i}$ & Use of neem seed kernel extract for worms and white fly & 18 & 7.50 & 82 & 34.17 & 140 & 58.33 \\
\hline ii & Use of neem cake/bar to control nematodes/ root disease & 10 & 4.17 & 40 & 16.67 & 190 & 79.17 \\
\hline iii & Ash/ cow dung slurry for control of pests and diseases & 36 & 15.00 & 46 & 19.17 & 158 & 65.83 \\
\hline iv & Application of ash & 22 & 9.17 & 54 & 22.50 & 164 & 68.33 \\
\hline $\mathbf{V}$ & Management of weed practices & & & & & & \\
\hline i & Keeping field bunds free from weeds & 220 & 91.66 & 10 & 4.17 & 10 & 4.17 \\
\hline ii & Timely inter-cultivation & 76 & 31.67 & 128 & 53.33 & 36 & 15.00 \\
\hline iii & Hand weeding & 222 & 92.50 & - & - & 18 & 07.50 \\
\hline iv & Bio-herbicides & - & - & 16 & 6.67 & 224 & 93.33 \\
\hline
\end{tabular}


Table.4 Association between adoption about management of EFPs of tribal farmers with their profile

\begin{tabular}{|c|c|c|c|}
\hline $\mathbf{S N}$ & Characteristics & $\chi^{2}$ & Degree of freedom \\
\hline 1 & Age & $8.047^{N S}$ & $4 D F$ \\
\hline 2 & Education & $33.291 * *$ & $8 D F$ \\
\hline 3 & Family size & $2.475^{N S}$ & $4 D F$ \\
\hline 4 & Social participation & $21.733 * *$ & $4 D F$ \\
\hline 5 & Size of land holding & $22.909 * *$ & $6 D F$ \\
\hline 6 & Annual income & $21.088 * *$ & $4 D F$ \\
\hline 7 & Economic Motivation & $24.344 * *$ & $4 D F$ \\
\hline 8 & Irrigation availability & $25.966 * *$ & $4 D F$ \\
\hline 9 & Material Possession & $25.828 * *$ & $4 D F$ \\
\hline 10 & Source of information & $20.089 * *$ & $4 D F$ \\
\hline 11 & Extension Contact & $19.779 * *$ & $4 D F$ \\
\hline 12 & Innovativeness & $23.562 * *$ & $4 D F$ \\
\hline 13 & Cosmopoliteness & $22.009 * *$ & $4 D F$ \\
\hline 14 & Scientific orientation & $19.857 * *$ & $4 D F$ \\
\hline 15 & Market Orientation & $21.223 * *$ & $4 D F$ \\
\hline 16 & $\begin{array}{l}\text { Attitude towards } \\
\text { cultivation }\end{array}$ & $27.356 * *$ & $4 D F$ \\
\hline
\end{tabular}

Table.5 Measures for minimizing the ill effects and properties of agrochemicals

\begin{tabular}{|c|c|c|c|}
\hline S. $\mathbf{N}$. & Suggestions made & Frequency & Percent \\
\hline 1 & $\begin{array}{l}\text { Ensure timely availability of pest resistant improved } \\
\text { varieties }\end{array}$ & 205 & 85.41 \\
\hline 2 & Organize awareness campaign on eco-friendly practices & 182 & 75.83 \\
\hline 3 & Encouraging farmers to cultivate organic farming & 170 & 70.83 \\
\hline 4 & Ensure firm quality control measures for pesticides & 158 & 65.83 \\
\hline 5 & $\begin{array}{l}\text { Encourage bio-pesticides and bio-fertilizers must be } \\
\text { increases }\end{array}$ & 130 & 54.17 \\
\hline 6 & $\begin{array}{l}\text { Promote bio-control agents in control of pests must be } \\
\text { increased }\end{array}$ & 119 & 49.50 \\
\hline 7 & Give premium price for organically growing vegetables & 84 & 35.00 \\
\hline 8 & $\begin{array}{l}\text { Educate and create awareness among public and farmers } \\
\text { about the environmental issues }\end{array}$ & 112 & 46.67 \\
\hline 9 & Establishing a network of farmers adopting organic farming & 74 & 31.66 \\
\hline 10 & Introducing ecological education at the school level & 82 & 34.16 \\
\hline
\end{tabular}


Measures for minimizing the ill effects and properties of agrochemicals

It has been experimented in the table 5 that the majority 85.41 percent of the respondents suggested to ensure timely availability of pest resistant improved varieties, followed by three-fourth of respondents said organizing awareness campaign on eco-friendly practices (75.83\%). Nearly two-third of respondents suggested heartening farmers to cultivate organic vegetables through subsides, technical support etc. (70.83\%) and ensure quality control measures for pesticides $(65.83 \%)$.

Encourage the use bio-pesticides and biofertilizers must be increased was suggested by 54.17 percent of the respondents. Nearly fifty percent of the respondents suggested about promotion and use of bio-control agents in control of pest must be increased (49.17\%). Out of 240 respondents 46.67 percent of the respondents advocated educating and creating the awareness among public and farmers about environmental issues. Thirty five per cent farmers suggested about giving premium price for organically grown vegetables. Introduction of ecological education at school level and establishing a network of farmers adopting organic farming was suggested by 34.16 per cent and 31.66 per cent, respectively.

In conclusion, higher percentage (49.17) of the respondents had medium adoption about eco friendly practices. A preponderance of the farmers 70.84 percent had partially adopted farm yard manure application. Most of the respondents 52.50 and 36.67 percent of the respondents had adopted crop rotation and inter cropping practices in vegetable. Majority of the farmers $(75.83 \%)$ had not applied any bio-fertilizer for growing vegetables. higher proportion of the respondents partially adopted the practices like splitting dose of application (60.83\%). Massive majority 97.92 percent farmers were found in non-adoption category regarding use of pheromone traps and use of light traps. Hundred percent of the farmers were found in non adoption category regarding practices such as conservation parasitic wasps. Majority 92.50 percent of the farmers had fully adopted the practices like use of hand weeding in standing crop closely. Majority 85.41 percent of the respondents suggested to ensure timely availability of pest resistant improved varieties, followed by three-fourth of respondents said organizing awareness campaign on eco-friendly practices $(75.83 \%)$.

\section{References}

Badodiya, S.K., Garg, S.K. and Shakya S.K. (2010) Knowledge of winter vegetable growers about eco-friendly practices. Asian J. Ext. Edu. 28(1\&2): 52-56.

Gour, C.L; S.K. Badodiya and Kamlesh Kumar (2014). Management of Ecofriendly Practices of agriculture among Tribal Farmers of Madhya Pradesh (India). SKUAST J. Res. 16 (1): 105112.

Maratha P., and Badodiya, SK. (2018) Study on Adoption of Eco-Friendly Management Practices by Vegetable Growers at Ladpura Block of Kota District in Rajasthan. Int. J. Pure App. Bioscience, 6(1): 1356-1361

Rajasree, R., F.L. Sharma and B. Upadhyay (2019) Association between the Characteristics of Vegetable Growers and Level of Adoption of Eco-Friendly Technologies in Vegetable Cultivation. Indian Res. J. Ext. Edu. 19(4): 86-88.

Shashidhara, K. K. and L. Manjunath (2008) Adoption of eco-friendly management practices by vegetable growers of North Karnataka. International J. of Agricultural Sciences. 4 (2): 480-484. 
How to cite this article:

Jagdish Morya, D. P. Rai and Badodiya, S. K. 2020. An Analytical Study on Management of Eco-Friendly Practices of Vegetable Crops among the Tribal farmers of Madhya Pradesh. Int.J.Curr.Microbiol.App.Sci. 9(04): 3036-3046. doi: https://doi.org/10.20546/ijcmas.2020.904.355 